\title{
Single-visit Apexification using Biodentin
}

\author{
${ }^{1}$ Faisal Nazar, ${ }^{2} \mathrm{~K}$ Radhakrishnan Nair, ${ }^{3} \mathrm{G}$ Praveena, ${ }^{4}$ Aadit Anilkumar, ${ }^{5}$ Ratheesh Rajendran
}

\begin{abstract}
Trauma to the tooth mainly results in pulpal injury, and these injuries during formative stage can result in incomplete root formation. This can result in failure in closure of root apex, resulting in wide open apex. This causes problem for the conventional root canal therapy as there is no apical stop against which the obturation material can be condensed. The management of a nonvital tooth with open apex is aimed at creation of an apical barrier. The newly introduced bioactive dentin substitute commercially available as biodentin is a promising material. It is a cement for stimulating hard tissue formation, i.e., the formation of reactive or reparative (tertiary) dentin. This case report describes the management of a traumatized permanent maxillary central incisor with an open apex.
\end{abstract}

Keywords: Apexification, Apical barrier, Biodentin, Open apex.

How to cite this article: Nazar F, Nair KR, Praveena G, Anilkumar A, Rajendran R. Single-visit Apexification using Biodentin. Cons Dent Endod J 2017;2(1):40-42.

Source of support: Nil

Conflict of interest: None

\section{INTRODUCTION}

Trauma to the tooth mainly results in pulpal injury, and these injuries during formative stage can result in incomplete root formation. This can result in failure in closure of root apex. Open apex causes problem for the conventional root canal therapy as there is no apical stop against which the obturation material can be condensed.

The management of a nonvital tooth with open apex is aimed at creation of an apical barrier. Since the conventional apexification using calcium hydroxide has certain drawbacks, like weakening of dentinal walls, porous barrier formation, and multiple visit for treatment completion, recent approach is to form an artificial apical plug using newer calcium silicate-based materials.

\footnotetext{
1,4,5 Postgraduate Student (3rd Year), ${ }^{2}$ Professor and Head ${ }^{3}$ Professor

${ }^{1-5}$ Department of Conservative Dentistry and Endodontics Azeezia College of Dental Science \& Research, Kollam, Kerala India

Corresponding Author: Faisal Nazar, Postgraduate Student (3rd Year), Department of Conservative Dentistry and Endodontics Azeezia College of Dental Science \& Research, Kollam, Kerala India, Phone: +914742531035, e-mail: faisalnazar8891782191@ gmail.com
}

Mineral trioxide aggregate (MTA) was the material of choice for apexification procedure because of its excellent sealing properties, biocompatibility, ${ }^{1}$ and reduced number of sittings. Studies have shown that MTA has capacity to induce odontoblastic differentiation, good radiopacity, low solubility, high $\mathrm{pH}$, and excellent antibacterial activity. The main drawbacks of MTA are its slow setting kinetics, potential to cause discoloration, and difficult handling property. ${ }^{2}$

However, the newly introduced bioactive dentin substitute, commercially available as biodentin, is a promising material. It is a cement for stimulating hard tissue formation, i.e., the formation of reactive or reparative (tertiary) dentin. Biodentin exhibits physical and chemical properties similar to certain Portland cement derivatives. Laurent et $\mathrm{al}^{3}$ have shown biodentin to be biocompatible compared with other materials. Based on all its properties, biodentin has been claimed to be a bioactive dentin substitute for the repair of root perforations, apexification, and retrograde root filling by the manufacturers.

This case report describes the management of a traumatized permanent maxillary central incisor with an open apex. The apical barrier used was biodentin.

\section{CASE REPORT}

A 27-year-old male patient reported to the department with compliant of discoloration in relation to upper front tooth. He had a history of trauma to the permanent maxillary right central incisor at the age of 9 years. The concerned tooth was dark brown in color and the dark shade fades away incisally (Fig. 1). Tooth was asymptomatic and showed no response to both electric and thermal pulp sensibility test. Radiographic examination revealed an open apex with associated periapical lesion of size $1 \mathrm{~cm}$ diameter in relation to involved tooth (Fig. 2). Based on the history and the radiographic findings, a diagnosis of asymptomatic apical periodontitis with an open apex was made in relation to maxillary right central incisor. Apexification with biodentin was planned, which ensures an obturation with effective seal.

Endodontic treatment was initiated and the access opening was done which caused the pus to drain through the opening. Working length was kept $2 \mathrm{~mm}$ short of apex (Fig. 3). The initial apical file was 40 size K-file. Copious irrigation was done with saline along with judicious use of sodium hypochlorite (3\%). Minimal instrumentation 


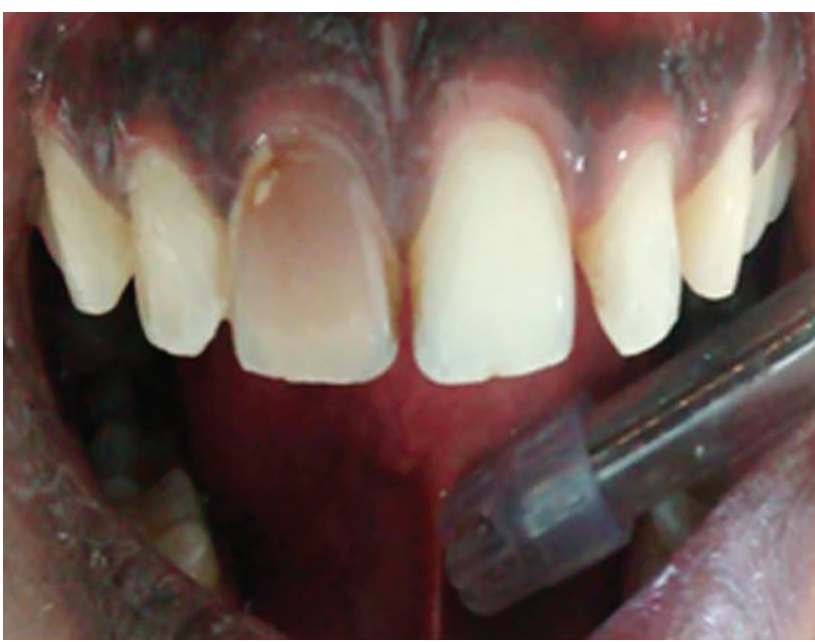

Fig. 1: Tooth showing discoloration

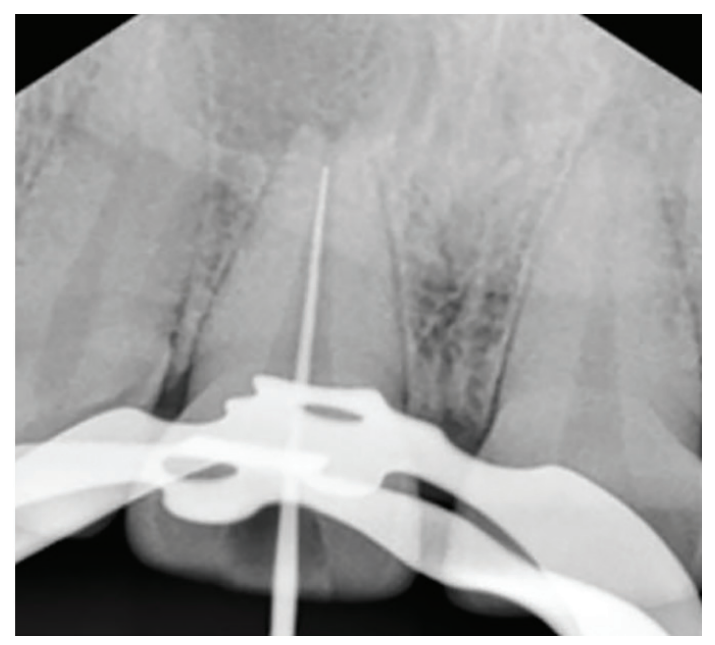

Fig. 3: Working length determination

was done. Calcium hydroxide intracanal medicament (RC cal, Primdent) was placed for 2 weeks.

Master cone was preselected $4 \mathrm{~mm}$ short of apex. Biodentin (Septodent, France) was mixed according to manufacturer's instruction and was placed with a carrier into the root canal. Preselected pluggers were used to condense the biodentin into an apical $4 \mathrm{~mm}$ barrier. The remainder of the root canal was obturated by cold lateral compaction technique (Fig. 4). Access cavity was sealed with zinc oxide eugenol. Follow-up examinations were carried out at 1 and 6 months respectively. During followup periods the involved tooth was asymptomatic and the postoperative radiographs taken at 6 months showed reduction in the size of the osseous lesion (Fig. 5). After 6 months recall, the treatment progress was accessed and metal ceramic crown given.

\section{DISCUSSION}

Apexification is defined as a method of inducing a calcified apical barrier of an incompletely formed root in

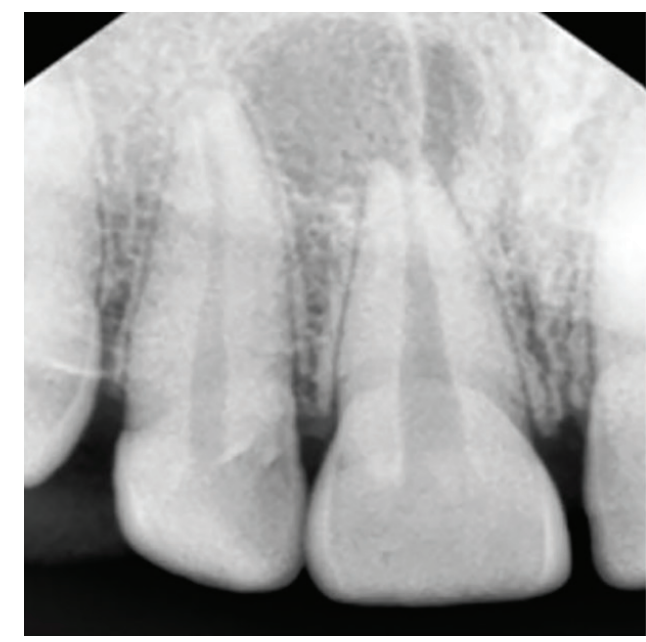

Fig. 2: Radiograph showing open apex

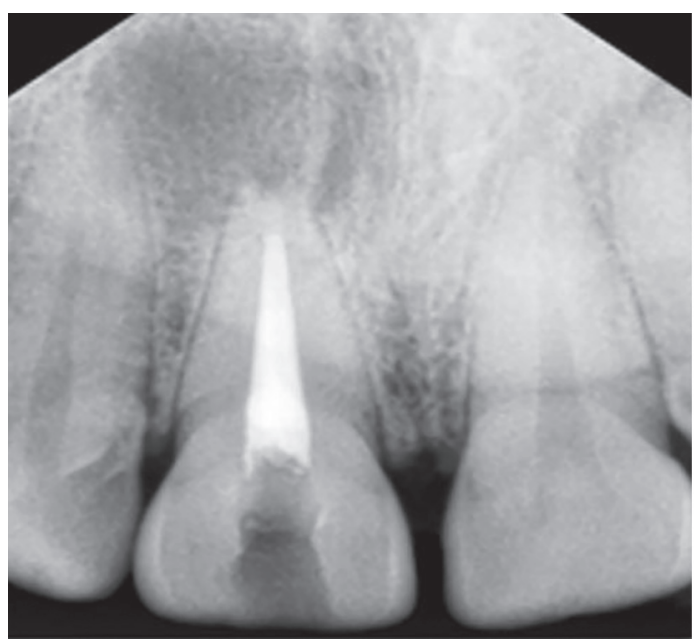

Fig. 4: Biodentin placement and obturation

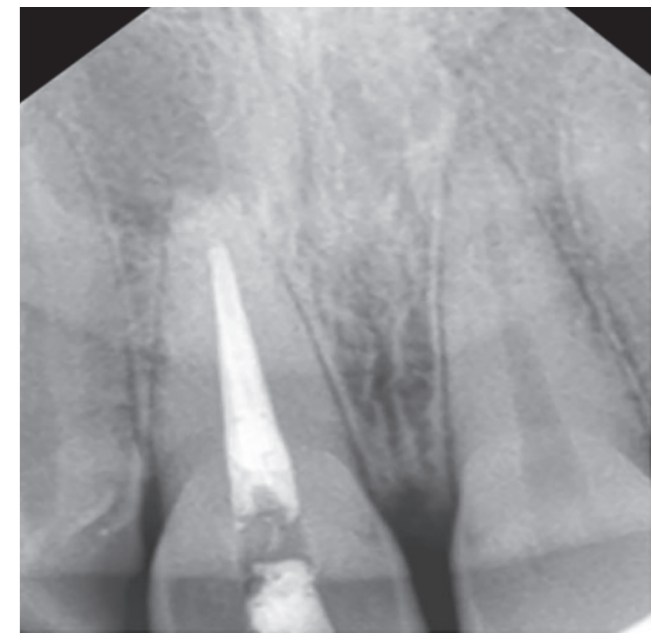

Fig. 5: Recall after 6 months

teeth with necrotic pulp. Calcium hydroxide was most commonly used medicament for apexification because, in addition to its low cost, its efficacy to induce the formation of an apical mineralized barrier is well documented. It has got some disadvantages like multiple visits required and 
it makes tooth brittle due to proteolytic and hygroscopic properties and the barrier formed with calcium hydroxide is porous and noncontinuous. The use of MTA apexification has become increasingly widespread. Biodentin can be used as an effective alternative to MTA as highlighted through this case presentation.

Apexification with biodentin requires significantly lesser treatment time. ${ }^{4}$ The patient compliance required is more in case of calcium hydroxide because of the multiple visits required. Also in case of biodentin, obturation can be done immediately after biodentin placement.

Biodentin is a calcium silicate-based material in which the powder component is mainly tricalcium silicate, dicalcium silicate, calcium carbonate, zirconium dioxide and liquid is calcium chloride in aqueous solution with an admixture of polycarboxylate.

Setting reaction is hydration reaction. Hydration of tricalcium silicate produces a hydrated calcium silicate gel and calcium hydroxide. The set mix consisting of unreacted tricalcium silicate grains are surrounded by layers of calcium silicate hydrated gel, which are relatively impermeable to water. The setting time of biodentin is 12 minutes.

Advantage of biodentin is that it does not stain tooth, it has micromechanical bonding so no surface preparation is required, and its microleakage resistance is enhanced by absence of shrinkage due to resin-free formulation and the material's biocompatibility.

Laurent et $\mathrm{al}^{5}$ were the first to show promising biological properties of biodentin on human fibroblast culture. In another study they have shown biodentin-induced mineralization foci formation early after its application and there was a significantly increased amount release of TGFbeta 1 from the pulp cells. ${ }^{6}$

Kokate and Pawar ${ }^{7}$ conducted a study that compared the microleakage of GIC, MTA, and biodentin when used as a retrograde filling material and concluded that biodentin exhibited the least microleakage when compared with other materials used. ${ }^{4}$ Research suggests that a high $\mathrm{pH}$ and released calcium ions are required for a material to stimulate mineralization in the process of hard tissue healing. Sulthan et $\mathrm{al}^{8}$ carried out a study to evaluate the $\mathrm{pH}$ and calcium ion release of MTA and biodentin when used as root end fillings. They concluded that biodentin presented alkaline $\mathrm{pH}$ and ability to release calcium ions similar to that of MTA. Aggarwal et $\mathrm{al}^{9}$ found out that 24-hour push-out strength of MTA was less than that of biodentin. Blood contamination affected the push-out bond strength of MTA Plus irrespective of the setting time.

The radiopacity for biodentin is lower in comparison with MTA. The content of the radiopacifier is zirconium oxide in biodentin differs from the bismuth oxide as a radiopacifier in MTA. The reason for such a preference might be due to some study results that show that zirconium oxide possesses biocompatible characteristics and is indicated as a bioinert material with favorable mechanical properties and resistance to corrosion. ${ }^{9}$ Also, the dentinlike radiopacity of biodentin helps demarcate between newly formed osseous barriers.

This case report emphasizes the novel approach of using biodentin to achieve single-visit apexification of the cases with an open apex and periapical lesion. The use of biodentin has been demonstrated to induce periapical healing for single-visit apexification of the cases with large periapical lesions.

\section{CONCLUSION}

The physical and biological properties of biodentin, associated with appropriate instrumentation and obturation techniques, make this material an excellent option in the endodontic therapy of immature permanent teeth.

\section{REFERENCES}

1. Saidon J, He J, Zhu Q, Safavi K, Spångberg LS. Cell and tissue reactions to mineral trioxide aggregate and Portland cement. Oral Surg Oral Med Oral Pathol Oral Radiol Endod 2003 Apr;95(4):483-489.

2. Parirokh $\mathrm{M}$, Torabinejad $\mathrm{M}$. Mineral trioxide aggregate: a comprehensive literature review - Part III: clinical applications, drawbacks, and mechanism of action. J Endod 2010 Mar;36(3):400-413.

3. Laurent P, Camps J, De Méo M, Déjou J, About I. Induction of specific cell responses to a $\mathrm{Ca}(3) \mathrm{SiO}(5)$-based posterior restorative material. Dent Mater 2008 Nov;24(11):1486-1494.

4. Wongkornchaowalit N, Lertchirakarn V. Setting time and flowability of accelerated Portland cement mixed with polycarboxylate superplasticizer. J Endod 2011 Mar;37(3): 387-389.

5. Laurent $\mathrm{P}, \mathrm{Camps} \mathrm{J}$, About I. Biodentine(TM) induces TGF- $\beta 1$ release from human pulp cells and early dental pulp mineralization. Int Endod J 2012 May;45(5):439-448.

6. About, I.; Laurent, P.; Tecles, O. Bioactivity of biodentine $\mathrm{T}^{\mathrm{TM}}$ CA3SiO5-based dentine substitute. Oral session. IADR Congress. Barcelona, Spain; 2010 Jul.

7. Kokate SR, Pawar AM. An in vitro comparative stereomicroscopic evaluation of marginal seal between MTA, glass ionomer cement and biodentine as root end filling materials using 1\% methylene blue as tracer. Endodontics 2012;2:36-42.

8. Sulthan IR, Ramchandran A, Deepalakshmi A, Kumarapan KS. Evaluation of $\mathrm{pH}$ and calcium ion release of mineral trioxide aggregate and a new root-end filling material. E J Dent 2012;2:166-169.

9. Aggarwal V, Singla M, Miglani S, Kohli S. Comparative evaluation of push-out bond strength of ProRoot MTA, Biodentine, and MTA Plus in furcation perforation repair. J Conserv Dent 2013 Sep;16(5):462-465. 